Lección inaugural del curso de 1922

\title{
Clínica Médica del hospital "Dos de Mayo"
}

Por el Dr. MAXIMILIANO GONZALES OLAECHEA

Catedrático de Clinica Médica en la Facultad de Medicina, de la Academia Nacional de Medicina de Lima

ESPUÉs de un largo periodo de interrupción de las tareas docentes, durante el cual ha sido puesta a dura prueba la fuerte estructura de nuestra Institución, volvemos, con los entusiasmos de siempre, a la grata labor de enseñanza de nuestra juventud médica.

Pero nos toca bacerlo, no ya en la. Cátedra de Clínica Propedética y Semiológica, que tuvimos el honor de fundar el año de 1906 y en la que hemos sido reemplazados por nuestros distinguido amigo el Dr. Anfbal Corvetto; sino en la de Clínica Médica de este hospital, cátedra cuya regencia nos ha sido encomendada por nuestros colegas de la Fa. cultad de Medicina, a quienes debemos reiterar, en esta oportunidad, nuestro profundo agradecimiento por el honor que han querido discernirnos tomando en consideración, más que mérito alguno, nuestra sincera devoción por los estudios médicos.

Deber nuestro es el recordar, en esta primera leccior de Clínica Médica, con la brevedad impuesta por la magnitud de la obra por ellos realizada, a los maestros que desempeñaronesta Cátedra desde la fnndación de la Facultad de Me. dicina, el año de 1856.

El Ductor Miguel E. DE Los Rios, fundador de la Cátedra en la Facultad, desempeñó la regencia de ella hasta el a- 
ño de 1881, en que ocurrí su sensible fallecimiento. Cónsiderado por sus contemporáneos como clínico notable, éste y otros merecimientos hicieron que sus compañeros le encomendaran la alta dirección de la Facultad de Medicina, que desempeñó por varios años.

El Doctor Leonardo Villar, que sucedió aldoctor Rios, ocupó la Cátedra hasta el año de su fallecimiento (1900). Profesional de vastos conocimientos, que compartió sus devociones entre la Medicina y la Filología, a la cual aportó una valiosa contribución, fué un clínico verdaderamente notable, cuyos merecimientos pudimos apreciar de cerca, por habernos sido dado desempeñar, en su servicio hospitalario, sucesivamente, los cargos de externo, interno y Jefe de Clinica y a quien recordamos con gratitud.

Sucedio al Doctor Villar, el Doctor Juan C. Castillo, faillecido prematuramente el año de 1904 y cuyos merecimientos de hábil y distinguido profesor son perfectamente conocidos de los contemporáneos.

Sucedió al anterior el Doctor ERNEsTo ODRIOzOLA, que ha regentado la Cátedra desde el año de 1905 hasta el de $1921, \in$ el que tuvo lugar su muy lamentable fallecimiento. Durante el largo período de tiempo dedicado a la enseñanza de esta Cátedra, el doctor Odriozor a llevó a cabo la obrá docente con realce extraordinario: sus lecciones clínicas han sido verdaderamente notables y en ellas se destaca, entre otros merecimientos, la extensa cultura médica del maestro. Eran las suyas lecciones plenas de concisión y de caridad, de brillante estilo. En los ámbitos de este recinto perdura el eco de las interesantes alocuciones del Doctor OdRIozola, cuya desaparición ha sido desgracia inmensa para la Facultad de Medicina por la calidad y número de las virtudes de que era poseed or el egregio maestro.

Muy honrados al ocupar la Cátedra dejada vacante por el querido maestro y amigo, procuraremos, en cuanto nos sea posible, seguir la buella luminosa suya e imitar, en parte siquiera, su bábil orientación docente.

Es en la Clínica Médica, señores, que perseguimos las más importantes finalidades de la Medicina. Contamos para llevar a cabo esta obra con el concurso de los conocimientos adquiridos en la Clínica Propedéutica y Semiológica, que nos sera base indispensable para efectuar el estudio analitico del enfermo y poder llegar al establecimiento del diagnós- 
tico, a la formulación del pronóstico y a establecer el tratamiento.

Los elementos con que contamos parà llegar a tan alta. finalidad son numerosos:

Los datos anamnésicos, próximos y remotos, del enfermo; asi como los antecedentes morbo'sos, hereditarios y fa. miliares.

Los procedimientos de exámen de la vieja Clínica que, lejos de haber sido relegados al olvido, han sido perfeccionados y ampliados.

Los diversos aparatos de expluración de los 6rganos y funciones muchos de los cuales ya son de ustedes conocidos.

Los variados procedimientos introducidos en la Clínica. para el mejor estudio de funciones de tanta importancia como la gástrica, la hepática, la pancreática y la renal.

Los resultados obtenidos por las investigaciones hematologicas, tanto en lo que se refiere a las alteraciones globu. lares, como en lo referente a la numeración y fórmula leucocitaria, a los caracteres físicos, a las modificaciones químicas y a los elementos bacteriológicos que pueda contener el líquido hemático.

Los resultados obtenidos por el exámen de diversos productos, tales como la expectoración, el jugo gástrico y el duodenal, el líquido céfalo raquídeo, los exudados o trasudados de las cavidades serosas: productos en los cuales debetán ser prolijamente investigados los caracteres físicos, químicos, citológicos, bacteriológicos y parasitarios.

No dejaremos de recurrir, cuando el caso lo imponga, a las diversas pruebas biológicas, tales como la Reacción de Von Pirquet, la de Mantoux, la Reacción de Widal, la de WASSERMANN, así como a todas aquellas reacciones biológicas fundadas en la desviación del complemento y las. cuales, án careciendo de un significado de información absoluta, desempeñan un rol importante en Clínica.

Procularemos utilizar, así mismo, la Radioscopía y la Radiografia, excelentes medios de exploración, aplicables en buen número de casos y cuya conveniente interpretación presta poderosa ayuda en la formulación del diagnóstico.

Por Gltimo, la investigacion anatomo patológica confirmará o rectificará nuestros diagnósticos $\mathrm{y}$, en uno u otro cosa, será una valiosa fuente de enseñanza. 
No es tarea fácil, señores, llegar a un verdadero diagnóstico. Se requiere, para ello, no olvidar la más pequeña circunstancia en la búsqueda de los elementos anamnésicos, verificar un examen metódico y completo de los órganos y funciones del enfermo. La omisión de investigaciones en apariencia insignificantes puede desviarnos del verdadero diagnóstico y conducirnos a incurrir en los más graves errores.

Observados estos preceptos, a pesar de haber extremado las precauciones en el examen del enfermo, es posible todavía escollar en el establecimiento del diagnóstico, ya por errores de interpretación de los fenómenos observados, errare humanum est, ya por la complejidad del caso que colocará al diagnóstico en el terreno de la hipótesis.

Para que el diagnóstico satisfaga ampliamente es indispensable que sepamos y podamos apreciar con exactitud la perturbación de las funciones, para poder pensar acerca de ella con criterio fisiologico, lo que nos conduciría a formular un diagnóstico fisio patologico. Tal la tendencia de los rlínicos modernos, a la cabeza de los cuales se encuentra el Profesor Grasset, de Montpellier 1; tal también la tendencia bosquejada por observadores anteriores: BroussaIs, Claudio Beriard, Litre, Robin, Huchard, quienes pensaban que la patología debía ser fisiologica.

Ahora bien, el diagnostico fisiopatologico trae o debe traer consigo el diagnóstico anatómico, o sea el conocimiento del asiento de la lesión; el diagnóstico sindromático, característico de la especie clínica; y debe propender a establecer la causa eficiente de lá enfermedad o afección, para poder formular el diagnóstico etiológico. Es así y solamente así que nos es dado llegar al perfecto diagnóstico o sea al integral, a aquel al que debemos aspirar siempre y a cuyro estudio dedica MARTINET muy interesantes páginas. 2

En la realidad clínica nos será dado verque este ideal no es siempre realizable: muchas veces nos faltarán uno o más elementos de tal diagnostico integral y nuestro diagnóstico sólo podrá ser incompleto o parcial.

En el estudio de los variados casos que se presentarán a nuestra observación ni desdeñaremos los antiguos conoci-

1-Physiopathologie Clinique.

2-Diagnostique Clinique. 
mientos ni echaremos en olvido los adelantos alcanzados por la Medicina en los últimos tiempos.

Así, por ejemplo, tratándose de enfermos del aparato cardio vascular tendremos presente la transformación que ha experimentado el estudio de las aritmias bajo el influjo de los descubrimientos anatomo-fisiológicos de His, Humblet, Frederico, Erlanger, Hering, Fawara, Keith y otros, comprobados en la Clínica por MACkenzIE, LFwis, en Inglaterra, ERLANGER, MAYER, Hewlet, en Estados U. nidos de Norte América, His, Hofmann, Hering, en Alemania, Vaquez, Gallavardin, Josué, Rutier y otros muchos en Francia, etc. y hacemos referencia solo a este capítulo por tratarse de la parte más resaltante de la patología cardiaca.

Adoptaremos tambien las nuevas enseñanzas en el estudio de los demás aparatos y órganos.

En más de una oportunidad nos veremos obligados a llamar la a tención de ustedes acerca de ciertos sindromes agudos del sistema nerrioso que pueden sobrevenir en el curso de las infecciones y de las intoxicaciones. En nuestra calidad de internistas no debemos ignorar la existencia de estos sindromes; debemos habituarnos a reconocerlos y este deber nuestro habrá de justificar nuestra intromisión en la Clínica Neurológica.

El enorme desarrollo recientemente alcanzado por el estudio d el simpático y para simpático, cuyo punto de partida fueran los estudios anatómicos de LANGLEX y GaskelL, las investigaciones químicas de Meyer e Higler, las observaciones clinicas de EPPINGER y Hiss, continuadas por $\mathrm{H}_{A R}$ VIER y otros, han abierto un nuevo campo de inrestigacion en la Patologia y han hecho posible el darse cuenta de que ciertos fenómenos clínicos eran debidos a una disfunción del sistema nervioso de la vida organo-vegetativa.

El simpático puede sufrir en su funcionamiento en diversos estados morbosos, tales como las toxi infecciones, las entermedades viscerales, las diátesis, el psiquismo emocional y, por último, como consecuencia de la disfunción de las glándulas endocrinas cuyos productos de secreción interna o harmozonas (yo gobierno) como los denomina Gley actuarian unas veces excitando (Hormonas) y otras deprimiendo (Chalonas) dicho sistema organo vegetativo. 
El funcionamiento del simpático y de las glándulas de secreción interna es solidario, siendo esta solidaridad de tal naturaleza que la disfunción de un produce perturbacion en las otras y vice versa, razbn por la cual muchos observadores, Guillaume (3) entre ellos, estudian conjuntamente la patología de ambos sistemas.

El rol más o menos importante que en los diversos esta. dos morbosos puede desempeñar el simpático, nos obligará, Fues, a prestar atención preferente a la investigación de los sindromes de hiper o hipofuncionamiento de dicho sistema, cuyo conocimiento tiene una enorme importancia no sólo desde el punto de vista especulativo sino también desdẹ el práctico, si recordamos la importancia considerable que desempeña el simpático en diversas funciones del organismo humano.

Posible que en el curso de nuestras observaciones clínicas, nos sea dado $\epsilon$ studiar los variados sindromes exponentes del hipo o hiperfuncionamiento de las glándulas de secreción interua, cuyo estudio, a pesar de hallarse en el interesante período inicial, ya ha arrojado bastante luz en la patología endocrinológica.

Señores: La labor que vamos a realizar es árdua; lo será mucho menos si contamos, como creemos deber contar, con la colaboración entusiasta y competente del jefe de Clínica Doctor BAMBAREN y con la enterá decisión de ustedes para el estudio. 